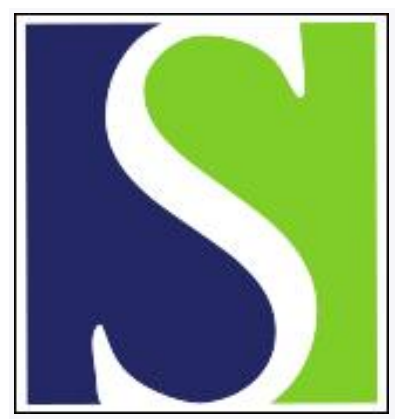

Scand J Work Environ Health 2020;46(3):321-329

https://doi.org/10.5271/sjweh.3860

Published online: 17 Nov 2019, Issue date: 01 May 2020

Precarious employment in occupational health - an OMEGA-NET working group position paper

by Bodin T, Çağlayan C, Garde AH, Gnesi M, Jonsson J, Kiran S, Kreshpaj B, Leinonen T, Mehlum IS, Nena E, Orellana C, Peckham T, Seixas N, Vanroelen C, Julià M

Despite the growing use of the term precarious employment, there is no consensus on a theoretical framework or definition. This hampers the study of the subject, especially in public and occupational health. We propose a theoretical framework for understanding precarious employment as a multidimensional construct where unfavourable features of employment quality accumulate in the same job. Future research should apply an intersectional and multi-level approach to analysis, with a focus on improving exposure assessment and investigating mechanisms.

Affiliation: Center for Occupational and Environmental Medicine, Solnavägen 4, SE-11364 Stockholm, Sweden. theo.bodin@ki.se

Refers to the following texts of the Journal: 2019;45(5):425-427 2019;45(5):429-443 2018;44(4):341-350 2014;40(4):343-352 2002;28(3):191-196

The following articles refer to this text: $2020 ; 46(3): 235-247$; 2021;47(2):117-126; 2021;47(2):108-116; 2021;47(3):171-180; 2021;47(7):509-520; 2022;48(1):61-70; 2022;48(4):312-321; 2022;48(5):327-350; 2022;48(5):351-360; 2022;48(8):591-597; 0;0 Special issue:0

Key terms: employment condition; non-standard employment; occupational health; OMEGA-NET; position paper; precarious employment; social determinant of health; working condition

This article in PubMed: www.ncbi.nlm.nih.gov/pubmed/31735974 


\title{
Precarious employment in occupational health - an OMEGA-NET working group position paper
}

\author{
by Theo Bodin, MD, PhD, ${ }^{1,2}$ Çiğdem Çağlayan, MD, ${ }^{3}$ Anne Helene Garde, PhD, ${ }^{4,5}$ Marco Gnesi, PhD, ${ }^{6}$ Johanna Jonsson, MSc, ${ }^{1}$ \\ Sibel Kiran, MD, PhD, ${ }^{7}$ Bertina Kreshpaj, MSc, ${ }^{1}$ Taina Leinonen, PhD, ${ }^{8}$ Ingrid S Mehlum, MD, PhD, ${ }^{9}$ Evangelia Nena, MD, PhD, ${ }^{10}$ \\ Cecilia Orellana, PhD, ${ }^{1}$ Trevor Peckham, MSc, ${ }^{11}$ Noah Seixas, PhD, ${ }^{11}$ Christophe Vanroelen, PhD, ${ }^{12}$ Mireia Julià, PhD 13, 14
}

\begin{abstract}
Bodin T, Çağlayan C, Garde AH, Gnesi M, Jonsson J, Kiran S, Kreshpaj B, Leinonen T, Mehlum IS, Nena E, Orellana C, Peckham T, Seixas N, Vanroelen C, Julià M. Precarious employment in occupational health - an OMEGA-NET working group position paper. Scand J Work Environ Health. 2020;46(3):321-329. doi:10.5271/sjweh.3860
\end{abstract}

\begin{abstract}
Objectives The aims of this position paper are to (i) summarize research on precarious employment (PE) in the context of occupational health; (ii) develop a theoretical framework that distinguishes PE from related concepts and delineates important contextual factors; and (iii) identify key methodological challenges and directions for future research on PE and health.

Methods This position paper is the result of a working group consisting of researchers from the EU, Turkey and the USA, who have discussed the issue over the course of six months (October 2018-April 2019), meeting both online and face-to-face on several occasions.

Results The lack of a common theoretical framework of PE hinders it from becoming an established part of occupational and public health research. There are also issues regarding operationalization in surveys and registers. Further, previous research on PE and health suffers from methodological limitations including inadequate study designs and biased assessments of exposure and outcomes. PE is highly dependent on contextual factors and cross-country comparison has proven very difficult. We also point to the uneven social distribution of PE, ie, higher prevalence among women, immigrants, young and low educated. We propose a theoretical framework for understanding precarious employment as a multidimensional construct.

Conclusions A generally accepted multidimensional definition of PE should be the highest priority. Future studies would benefit from improved exposure assessment, temporal resolution, and accounting for confounders, as well as testing possible mechanisms, eg, by adopting multi-level and intersectional analytical approaches in order to understand the complexity of PE and its relation to health.
\end{abstract}

Key terms employment condition; non-standard employment; social determinant of health; working condition.

1 Unit of Occupational Medicine, Institute of Environmental Medicine, Karolinska Institutet, Stockholm, Sweden.

2 Center for Occupational and Environmental Medicine, Stockholm Region, Stockholm, Sweden.

3 Kocaeli University, Faculty of Medicine, Department of Public Health, Kocaeli, Turkey.

4 National Research Centre for the Working Environment, Copenhagen, Denmark.

5 Department of Public Health, University of Copenhagen, Denmark.

6 Department of Public Health, Experimental Health and Forensic Medicine, University of Pavia, Pavia, Italy.

7 The Department of Occupational Health and Safety, Institute of Public Health, Hacettepe University, Ankara, Turkey.

8 Finnish Institute of Occupational Health, Helsinki, Finland.

9 National Institute of Occupational Health, Oslo, Norway.

${ }^{10}$ Medical School, Democritus University of Thrace, Alexandroupolis, Greece.

11 Department of Environmental and Occupational Health Sciences, University of Washington, Seattle, USA.

12 Interface Demography, Department of Sociology, Vrije Universiteit Brussel, Belgium.

13 Health Inequalities Research Group, Employment Conditions Knowledge Network (GREDS-EMCONET), Department of Political and Social Science, Universitat Pompeu Fabra, Barcelona, Spain.

14 Johns Hopkins University-Universitat Pompeu Fabra Public Policy Center, Barcelona, Spain.

Correspondence to: Theo Bodin, Center for Occupational and Environmental Medicine, Solnavägen 4, SE-11364 Stockholm, Sweden. [Email: theo.bodin@ki.se] 
There is a growing recognition of the myriad ways in which employment and work contribute to the health of populations. In addition to traditional occupational hazards, such as dusts, chemicals, injury risks and psychosocial stressors, there is an increasing appreciation of how aspects of the employment relationship, referring to the terms and conditions by which an organization (business, public, or non-profit entity) pays someone to work for them, can be a social determinant of health. Various lines of evidence suggest that the overall quality of employment relationships in developed economies has significantly degraded in the last decades $(1,2)$. Moreover, because employment quality is commonly associated with sociodemographic profiles, these trends have led to mounting concern about the role of employment in contributing to health disparities across working populations (3). These concerns have been incorporated into a broad conception of an array of employment conditions through the term 'precarious employment' (PE). However, despite the growing use of the term, and the multiple efforts to define this concept, no clear consensus has emerged. Thus, research of the health implications of PE has been hampered.

The EU-funded Network on the Coordination and Harmonisation of European Occupational Cohorts, OMEGA-NET (omeganetcohorts.eu), recognizes the importance of the issue and supports the development of epidemiological research on PE. This position paper is the result of a working group consisting of researchers from the EU, Turkey and the USA, who have discussed the issue over the course of six months from October 2018 to April 2019. It is hoped that through refinement of the PE concept, a clearer consensus on its operationalization can be adopted for its integration into research on the health of working populations of Europe and beyond. Further, by addressing issues of PE in the context of these large cohort studies, a research agenda can be developed to focus research on questions with the greatest potential for improving the health and well-being of a large number of workers.

Specifically, the aims of this paper are to (i) summarize research on $\mathrm{PE}$ in the context of occupational health; (ii) develop a theoretical framework that distinguishes PE from related concepts and delineates important contextual factors; and (iii) identify key methodological challenges and directions for future research on PE and health.

\section{Lack of a common definition of precarious employment}

Despite thriving in fields such as economics and sociology, there are still barriers preventing PE from becoming an established part of occupational and public health research some of which have recently been pointed out in an editorial in this journal (4).
There is substantial confusion when it comes to the concept of PE, as many related terms are used interchangeably: 'the precariat', 'precarious work' or simply 'precarity' or 'precariousness'. In the EU, 'atypical' or 'nonstandard' forms of employment have been used widely instead of, or as synonyms for, PE, whereas in the US the term 'contingent work' is more common (5). Another concept used in the occupational health literature is 'employment quality', which refers to the employment conditions and employment relations together (6). Employment quality can be conceived as a continuum, where PE is at the disadvantaged end due to an accumulation of unfavorable facets of employment quality.

Fundamentally, there is no universally accepted definition of PE that can transcend sociopolitical and historical context. Starting with the foundational work of Rodgers \& Rodgers in the 1980s (7), four main dimensions of PE were identified: (i) employment instability, (ii) employment insecurity (limited control, collective or individual, over working conditions, wages and place of work), (iii) erosion of workers' protection and (iv) low material rewards. Building on this work, several researchers and institutions have adopted and developed their own definitions and operationalizations and studied these within a public health context (7-12). However, none of these have gained enough traction from researchers and practitioners to become the "standard definition". Therefore, PE has not been integrated into routine surveillance instruments, such as labor force or working conditions surveys, making longitudinal, population-based studies on the topic rare and international comparison infeasible. From a public health perspective, compared to research on psychosocial work environment launched by Karasek in 1979 (13), research on PE has achieved far less attention as an "occupational health threat" from practitioners and policy-makers. In public health research, PE has often been reduced to 'single dimensions' (of employment quality), such as temporary or part-time employment. Too often, it has been used synonymously for self-perceived job insecurity, a psychological (cognitive and/or affective) phenomenon (14), which we consider a consequence rather than an objective measure of PE.

\section{Previous operationalization and measurement}

To date, only two validated questionnaires have been developed for the sole purpose of measuring PE in a public health context. Researchers affiliated with the GREDS-EMCONET (Health Inequalities Research Group - Employment Conditions Network) in Barcelona developed the Employment Precariousness Scale (EPRES), which includes six dimensions: "temporariness" (contract duration), "disempowerment" (level of negotiation of employment conditions), "vulnerability" 
(defenselessness to authoritarian treatment), "wages" (low or insufficient; possible economic deprivation), "rights" (such as paid vacations, parental leave, sickleave benefits and pensions), and "exercise rights" (powerlessness, in practice, not being able to exercise the workplace rights listed previously without obstacles) (11). So far, the EPRES scale has only been employed in studies of working populations in Spain $(15,16)$, Chile (17), and Sweden (18). The only other purpose-specific survey instrument to measure PE is from Canada. In the longitudinal survey Poverty and Employment Precarity in Southern Ontario (PEPSO) 2011-2014, the Employment Precarious Index was created based on ten questions covering: income level, income security, employment security, schedule predictability, contract type, employment-related benefits, fear of raising concerns at the workplace (lack of rights/vulnerability), and receiving salary in cash (risk factor for undeclared salary in the Canadian context) (19).

Due to the challenges and costs of creating and validating purpose-specific surveys, many studies have attempted to exploit existing data to characterize PE using proxy indicators within labor, economic, health, or social surveys. The list of surveys used to study PE (or related constructs) and health is long; some notable examples include the European Working Conditions Survey (6, 20-23), European Labour Force Survey (24), Gender and Generations Study in Belgium (25), Catalan Working Conditions Survey in Catalonia (16), the US General Social Survey (26), and Canadian Survey of Labor and Income Dynamics (27). All but the last of these are cross-sectional studies, limiting the scientific value of resulting analyses to hypothesis generation and theory development. The few extant examples of longitudinal analyses provide more support for the causal relationship - for example, by controlling for baseline health or examining employment trajectories $(27,28)$ - but have limited generalizability and comparability to other studies using other sets of questions (29). Although studies employing secondary data analysis are inherently limited, the use of proxies facilitates the development of large-scale and cross-national evidence using existing data sources (20).

Records from government agencies, hospitals, large employers, insurance firms or other organizations can contain employment-related variables, which could be used to operationalize PE. A few studies have used register data to study employees who have a large number of contracts (30), frequent job changes (31), or fixedterm contracts (32-34). Ongoing work to operationalize a multi-dimensional construct of $\mathrm{PE}$ in routine register data is under way in Sweden and Denmark, and attempts have also been made in Belgium.

In addition to choice of indicators, several approaches to operationalizing a multidimensional construct of PE are present in the health literature. One approach is to include multiple indicators of PE within multivariable regression analysis (27). This approach thus examines associations between individual indicators and health, while controlling for all others. A second, and the most common approach is to create a composite or summed scale variable, measuring a worker's relative position along a continuum of low to high precariousness $(35,36)$. This approach can be used to examine whether health is associated with an accumulation of poor employment conditions. A third approach is to construct a typology of employment arrangements, conceptualizing jobs as packages of employment features and thus allowing for examination whether specific patterns of exposure are associated with health. Studies using a typological approach have most commonly used latent class analysis to model types of employment arrangements $(6,25,26)$. We do not recommend a specific approach, but encourage researchers to make careful considerations when designing a study.

\section{Precarious employment and health}

Despite the limited agreement on definition and operationalization of PE, a growing number of studies have focused on the health effects of PE during the last decades. Recent systematic reviews show that multidimensional indicators as well as various separate dimensions of PE may be linked to an array of health issues including mental and physical ill-health $(3,29)$ and occupational injuries (37), as well as health-related behaviors such as higher levels of smoking (38) and lower access to healthcare (39). There are also studies showing associations between $\mathrm{PE}$ and higher risk of childlessness/postponed parenthood (40) and risk of disability pension (41). One study investigated relations with satisfaction with working conditions (6).

The mechanisms linking PE and health are not yet fully understood $(20,42,43)$. Three main pathways have been suggested (i): working conditions with harmful health consequences are more frequently experienced by workers with PE (ii); poor employment conditions associated with PE may lead to adverse health outcomes by limiting worker's control over their professional and personal lives; and (iii) PE may produce incomes below the subsistence level, which may consequently affect various social determinants of health (eg, housing quality, adverse lifestyle etc.) (20).

Investigating the relation between $\mathrm{PE}$ and health is complicated because of bidirectional or reverse causation and health selection effects (44). In a recent review of longitudinal studies on PE and mental health, many studies had serious limitations in design, including measurement of exposure and outcomes at the same time-point and lack of appropriate baseline adjustments 
(29). Because employees may change employment status throughout life - and precarious employees even more so - using only one time-point for exposure measurement may result in misclassification of exposure, a problem which has only been handled in very few studies (28). Further, many survey-based studies suffer from the use of subjective measures of both exposure and outcomes adding to risk of common method bias (occurring eg, when both exposures and outcomes are self-reported).

Applying work-life trajectories would take several of the limitations in previous studies into account and has the potential to create a bridge to sociology, ethnography, and economics, where the process of precarisation is a major focal point of interest.

Although several studies have applied multidimensional constructs, most studies with stated aims to investigate the association between $\mathrm{PE}$ and health depend on single aspects of employment arrangements, such as non-standard or temporary employment contracts. Recent reviews have found no overall clear direction of associations between temporary contracts and mental health $(29,45)$ or occupational injuries (37). Yet, longitudinal studies applying various multidimensional exposure constructs have found stronger mental health effects of PE than those seen when studying parts of the phenomenon as single-item variables (29). This adds to the already strong case for applying a multi-dimensional approach with objective measures (46).

\section{Labor market context and welfare regimes}

Due to the lack of a common definition, relevant comparisons between countries and continents are extremely difficult. Based on multidimensional operationalizations in surveys in the EU, the prevalence of PE has been found to be higher in Southern and Eastern European countries and lower in the Nordic countries, although the detailed picture is more nuanced $(47,48)$.

In Anglo-Saxon or "liberal" welfare regimes such as the USA, the term "contingent work" is commonly used instead of PE. However, very few workers fall within this category (49), highlighting the fact that employers in these countries have little need or incentive to create explicitly temporary jobs, since open-ended contracts can easily be terminated. On the contrary, temporary employment is more common in East-Asian welfare regimes such as Korea and Japan (50), which are generally characterized by low levels of governmental intervention and investment in social welfare, less developed public service provision, and a strong reliance on family and the voluntary sector in welfare provision (51).

A strong welfare system can alleviate some of the effects of PE. However, in some countries with strong welfare systems, PE might increase the risk of not qualifying for social security schemes, as these were built to cater for workers in a "standard employment relation". The lack of social (and OHS) protection for precarious employees could further increase the differences in health and well-being. Strong welfare regimes have also developed in countries with strong unions and labor laws, which further confounds and complicates the study of these issues. Others have called for a systems approach (42), stating this is necessary to understand the interaction between social and institutional regulatory protection and $\mathrm{PE}$.

\section{Axes of inequality}

Exploring the intersecting axes of inequality among those in $\mathrm{PE}$ is crucial to understanding both the social distribution of PE and its differential effects (52). Several studies have found a higher prevalence of PE among women, young workers, manual workers, and immigrants $(22,53)$. The more of these inequality characteristics that accumulate in the same person, the higher the prevalence of employment precariousness (36). One publication from Chile compared the association between psychological distress and PE and found it to be significantly higher in women (54).

Research gaps persist whether these inequalities in employment relationships contribute to gender differences in adverse health outcomes.

Standing (8) underlines how the migrant population covers a large share of the world's precariat. Studies have further shown how recently arrived migrants are more likely to be engaged in temporary and agency work and to have insecure and poor working conditions (55-57). Recently arrived migrants often have limited access to legal expertise, collective bargaining, and union representation, and consequently end up accepting the most precarious labor contracts, sometimes also informal employment (57-59).

\section{Research agenda}

Theoretical framework for a common definition. Despite a rapidly growing empirical and theoretical literature, a generally accepted multidimensional definition of $\mathrm{PE}$ is lacking - an issue of the highest priority. A critical first step to advancing research on PE and health is conceptual clarity. We propose a theoretical framework for understanding PE as a multidimensional construct where unfavorable features of employment quality accumulate in the same job (figure 1). Thus, conceptualization and measurement of PE for occupational health research occurs at the level of the employment relationship. Examples of important employment conditions that constitute this relationship are level of pay and other 
non-wage benefits, workplace rights and representation, and length or type of contract. We do not aim to list all possible aspects of employment relations that could be included, rather we encourage an open discussion on that matter.

The types of employment found in a labor market are influenced by global economic, technological, social, and political trends, such as globalization processes and weakening labor representation. These macro-level trends and factors are upstream and antecedent of PE, for example, having contributed to a general increase in the prevalence of sub-contracting, outsourcing, consulting, and newer forms of gig and platform work. Macro-level trends also interact with international and national labor rights legislation, regulations, and collective agreements.

From our theoretical framework, it follows that hazardous, boring or dissatisfying work should be seen as possible consequences of $\mathrm{PE}$, rather than characteristics of precarious work itself. The same holds for psychological (cognitive and/or affective) perceptions of job insecurity, social precarisation (poverty, "life" insecurity, etc.) and adverse health outcomes, which we believe are conceptually on another level, downstream from the PE. Furthermore, the component of contractual instability, which is more related to job insecurity, could be addressed by measuring type of contract, objective treats to the continuity of employment.

We further highlight the importance of policy and social contexts, which may be key modifying (or moderating) factors that influence the nature of $\mathrm{PE}$ in specific contexts, as well as the PE-health relationship but that are not included in measurement of the construct. In other words, the nature and consequences of a given employment relationship may differ depending on contextual factors like regulatory protections or availability of social insurance, as well as across different sociodemographic groups and workers' social context.

Without a common definition of PE to guide operationalization of the concept, cross-study and crosscountry comparisons and meta-analyses will continue to be elusive.

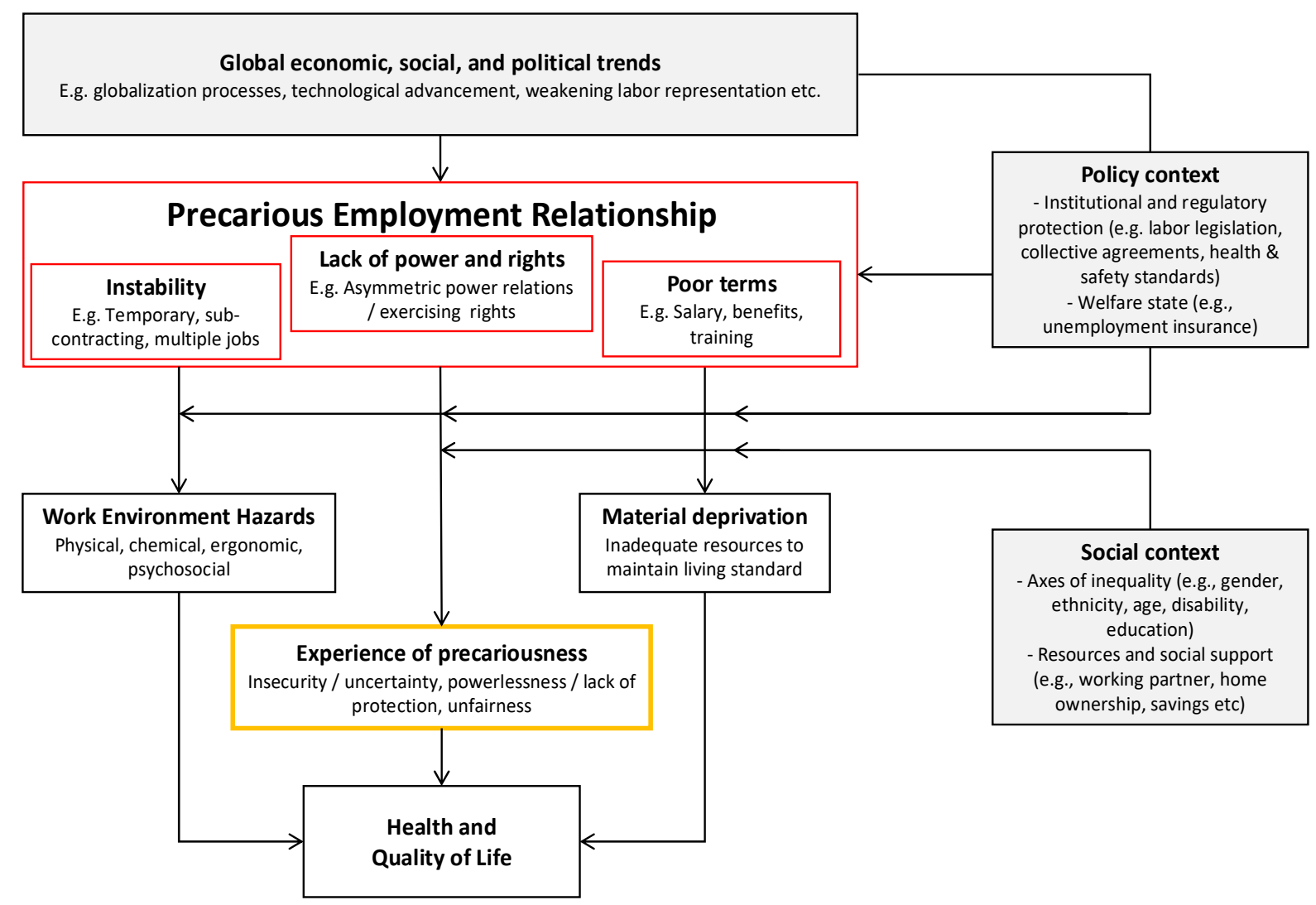

Figure 1. Theoretical framework for precarious employment. 
Future research on PE and health would benefit from (i) an open and interdisciplinary process to reach consensus on a definition of $\mathrm{PE}$ and/or employment quality; (ii) guidelines for standardized reporting of data in order to increase the comparability between studies; and (iii) inclusion of a core set of questions into different panel surveys such as the European Working Conditions and Labour Force surveys, etc.

\section{Intersectional and multi-level analysis}

Using our proposed theoretical framework, we aim to clarify the various relevant levels of analyses, beginning with the level of the employment relationship. Moving upstream, analyses should continue to clarify the antecedents of different employment forms - both across jurisdictions and over time - to inform potential interventions and policy aimed at reducing the prevalence of PE. However, most research in occupational and public health in this area will be oriented downstream of the employment relationship. For instance, further analyses are needed to clarify mechanistic pathways leading to ill health, such as characteristics of the work environment, adequacy of job-related material rewards, and direct psychological impacts from PE relations. Further, it is important to account for policy and social contexts that are likely to modify/moderate these pathways. In particular, theory and evidence suggest that individual experiences of precariousness are heavily influenced by these contexts $(52,60)$. Ultimately, the goal of occupational health epidemiology is to identify job-related determinants of worker health; thus, distinguishing between the employment relationship and other factors is important to guide workplace and regulatory policy interventions. However, because of the complex and embedded nature of PE within multiple layers of context, we argue that a deeper understanding of the role of $\mathrm{PE}$ in producing health will occur when we disentangle the relationships across all of these levels as suggested in previous work (61). This approach differs from other research focused on the level of precarious workers or a precariat social class.

\section{Better longitudinal studies for health}

Research on PE and health lacks longitudinal studies of high-quality, ie, design, objective exposure and outcome measurement and standardized reporting of results. Thus, future research on PE and health would benefit from:

1. Improved exposure assessment, temporal resolution, and accounting for confounding:

- More longitudinal studies on PE $(2,4,6)$ and health.
- Use of a combination of data sources to minimize reporting bias.

- Better resolution of timing of the exposure, eg, by examining employment trajectories. Studying employment trajectories can provide knowledge on how effects of PE accumulate across time, the transient or chronic nature of possible effects, and if these effects are modified by other factors (4).

- Better use of register data, providing information that is both objective and repeatedly measured, highly useful for operationalization.

- Careful considerations when selecting the sources of data on precarious employees. Precarious employees may be on hourly contracts, which can affect the registration of the outcome, eg, for occupational injuries, when the outcome is registered as days of absence due to injury (6).

2. Mechanisms and mediator studies:

- Detailed study on the mechanisms/pathways relating precariousness to (specific) health and well-being outcomes.

- Clinical studies with biological sampling should be seriously considered.

3. Studies on other outcomes, such as:

- Cardiovascular and respiratory diseases

- Associations with biomarkers of which relationship with stress-related diseases is demonstrated

- There are very few studies on the relation/coexistence of PE and hazardous work environment, a pathway that should be explored.

\section{Concluding remarks}

A commonly accepted multidimensional definition of PE should be one of the highest priorities in the occupational safety and health field. Adopting a multi-level and intersectional analytical approach in future studies is key to understanding the complex processes of $\mathrm{PE}$ and their relation to health.

\section{Acknowledgments}

The authors would like to thank OMEGA-NET core group for its support.

\section{Funding statement}

The European Union financed the work of this task group (COST Action CA16216). The funder had no role in its design, search and analysis, decision to publish, or preparation of the manuscript. 


\section{Ethics statement}

This position paper does not require ethical approval

\section{Conflicts of interest}

The authors declare no conflicts of interest.

\section{References}

1. Kalleberg AL. Good jobs, bad jobs: The rise of polarized and precarious employment systems in the United States, 1970s-2000s: Russell Sage Foundation; 2011.

2. Della Porta D, Silvasti T, Hänninen S, Siisiäinen M. The new social division: Making and unmaking precariousness: Springer; 2016.

3. Benach J, Vives A, Amable M, Vanroelen C, Tarafa G, Muntaner C. Precarious employment: understanding an emerging social determinant of health. Annu Rev Public Health 2014;35(1):229-53. https://doi.org/10.1146/annurevpublhealth-032013-182500.

4. Ervasti J, Virtanen M. Research strategies for precarious employment. Scand J Work Environ Health. 2019;45(5):4257. https://doi.org/10.5271/sjweh.3845.

5. Quinlan M. The 'Pre-Invention' of Precarious Employment: The Changing World of Work in Context. Econ Labour Relat Rev. 2012;23(4):3-24. https://doi.org/10.1177/10353046120 2300402 .

6. Van Aerden K, Puig-Barrachina V, Bosmans K, Vanroelen C. How does employment quality relate to health and job satisfaction in Europe? A typological approach. Soc Sci Med. 2016;158:132-40. https://doi.org/10.1016/j. socscimed.2016.04.017.

7. Rodgers G, Rodgers J. Precarious jobs in labour market regulation: the growth of atypical employment in Western Europe: International Labour Organisation; 1989.

8. Standing G. The precariat: The new dangerous class: Bloomsbury Publishing; 2011.

9. International Labour Organization (ILO). From precarious work to decent work: outcome document to the workers' symposium on policies and regulations to combat precarious employment. Geneva: ILO, Bureau for Workers' Activities, 2012.

10. Tompa E, Scott-Marshall H, Dolinschi R, Trevithick S, Bhattacharyya S. Precarious employment experiences and their health consequences: towards a theoretical framework. Work. 2007;28(3):209-24.

11. Vives A, Amable M, Ferrer M, Moncada S, Llorens C, Muntaner $\mathrm{C}$ et al. The Employment Precariousness Scale (EPRES): psychometric properties of a new tool for epidemiological studies among waged and salaried workers. Occup Environ Med. 2010;67(8):548-55. https://doi. org/10.1136/oem.2009.048967.
12. Vosko LF. Precarious employment: Understanding labour market insecurity in Canada: McGill-Queen's University Press Quebec; 2006.

13. Karasek RA Jr. Job demands, job decision latitude, and mental strain: implications for job redesign. Adm Sci Q. 1979;24(2):285-308. https://doi.org/10.2307/2392498.

14. Shoss MK. Job Insecurity: An Integrative Review and Agenda for Future Research. J Manage. 2017;43(6):191139. https://doi.org/10.1177/0149206317691574.

15. Vives A, Gonzalez F, Moncada S, Llorens C, Benach J. Measuring precarious employment in times of crisis: the revised Employment Precariousness Scale (EPRES) in Spain. Gac Sanit. 2015;29(5):379-82. https://doi.org/10.1016/j. gaceta.2015.06.008

16. Benach J, Julià M, Tarafa G, Mir J, Molinero E, Vives A. La precariedad laboral medida de forma multidimensional: distribución social y asociación con la salud en Cataluña. [Multidimensional measurement of precarious employment: social distribution and its association with health in Catalonia (Spain)]. Gac Sanit. 2015;29(5):375-8. https://doi. org/10.1016/j.gaceta.2015.04.002.

17. Vives-Vergara A, González-López F, Solar O, BernalesBaksai P, González MJ, Benach J. Precarious employment in Chile: psychometric properties of the Chilean version of Employment Precariousness Scale in private sector workers. Cad Saude Publica. 2017;33(3):e00156215. https://doi. org/10.1590/0102-311x00156215.

18. Jonsson J, Stein M, Johansson G, Bodin T, Strömdahl S. A performance assessment of web-based respondent driven sampling among workers with precarious employment in Sweden. PLoS One. 2019;14(1):e0210183. https://doi. org/10.1371/journal.pone.0210183.

19. Lewchuk W. Precarious jobs: where are they, and how do they affect well-being? Econ Labour Relat Rev. 2017;28(3):40219. https://doi.org/10.1177/1035304617722943.

20. Julia M, Vanroelen C, Bosmans K, Van Aerden K, Benach J. Precarious Employment and Quality of Employment in Relation to Health and Well-being in Europe. Int J Health Serv. 2017;47(3):389-409. https://doi.org/ $10.1177 / 0020731417707491$.

21. Benavides FG, Benach J, Diez-Roux AV, Roman C. How do types of employment relate to health indicators? Findings from the second European survey on working conditions. J Epidemiol Community Health. 2000;54(7):494-501. https:// doi.org/10.1136/jech.54.7.494.

22. Puig-Barrachina V, Vanroelen C, Vives A, Martínez JM, Muntaner C, Levecque $\mathrm{K}$ et al. Measuring employment precariousness in the European Working Conditions Survey: the social distribution in Europe. Work. 2014;49(1):143-61.

23. Julià M, Belvis F, Vives A, Tarafa G, Benach J. Informal employees in the European Union: working conditions, employment precariousness and health. J Public Health (Oxf). 2019;41(2):e141-e151. https://doi.org/10.1093/ pubmed/fdy111.

24. Kretsos L, Livanos I. The extent and determinants of 
precarious employment in Europe. Int J Manpow. 2016; 37(1):25-43. https://doi.org/10.1108/IJM-12-2014-0243.

25. Van Aerden K, Gadeyne S, Vanroelen C. Is any job better than no job at all? Studying the relations between employment types, unemployment and subjective health in Belgium. Arch Public Health. 2017;75(1):55. https://doi. org/10.1186/s13690-017-0225-5.

26. Peckham T, Fujishiro K, Hajat A, Flaherty BP, Seixas N. Evaluating Employment Quality as a Determinant of Health in a Changing Labor Market. RSF. 2019;5(4):258-81. https://doi.org/10.7758/rsf.2019.5.4.09.

27. Scott-Marshall H, Tompa E. The health consequences of precarious employment experiences. Work. 2011;38(4):369-82.

28. Canivet C, Bodin T, Emmelin M, Toivanen S, Moghaddassi $\mathrm{M}$, Östergren PO. Precarious employment is a risk factor for poor mental health in young individuals in Sweden: a cohort study with multiple follow-ups. BMC Public Health. 2016; 16(1):687. https://doi.org/10.1186/s12889-016-3358-5.

29. Rönnblad T, Grönholm E, Jonsson J, Koranyi I, Orellana C, Kreshpaj B et al. Precarious employment and mental health: a systematic review and meta-analysis of longitudinal studies. Scand J Work Environ Health. 2019;45(5):429-43. https://doi.org/10.5271/sjweh.3797.

30. Duran X, Martínez JM, Benavides FG. Occupational factors associated with the potential years of working life lost due to a non-work related permanent disability. Work. 2013;45(3):305-9.

31. Hougaard CO, Nygaard E, Holm AL, Thielen K, Diderichsen F. Job mobility and health in the Danish workforce. Scand J Public Health. 2017;45(1):57-63. https://doi.org/10.1177/1403494816680785.

32. Virtanen M, Kivimäki M, Ferrie JE, Elovainio M, Honkonen T, Pentti J et al. Temporary employment and antidepressant medication: a register linkage study. J Psychiatr Res. 2008;42(3):221-9. https://doi.org/10.1016/j. jpsychires.2006.12.005.

33. Ervasti J, Vahtera J, Virtanen P, Pentti J, Oksanen T, Ahola K et al. Is temporary employment a risk factor for work disability due to depressive disorders and delayed return to work? The Finnish Public Sector Study. Scand J Work Environ Health. 2014;40(4):343-52. https://doi.org/10.5271/sjweh.3424.

34. Zaballa E, Martínez JM, Duran X, Albertí C, Gimeno Ruiz de Porras D, Benavides FG. Incidence of sickness absence by type of employment contract: one year followup study in Spanish salaried workers. Arch Public Healt.h 2016;74(1):40. https://doi.org/10.1186/s13690-016-0152-x.

35. Sparke M. Introducing globalization: The ties that bind. Chichester, UK: Wiley-Blackwell; 2013.

36. Vives A, Vanroelen C, Amable M, Ferrer M, Moncada $\mathrm{S}$, Llorens C, et al. Employment precariousness in Spain: prevalence, social distribution, and population-attributable risk percent of poor mental health. Int J Health Serv. 2011;41(4):625-46.

37. Koranyi I, Jonsson J, Rönnblad T, Stockfelt L, Bodin T. Precarious employment and occupational accidents and injuries - a systematic review. Scand J Work Environ Health. 2018;44(4):341-50. https://doi.org/10.5271/sjweh.3720.

38. Jung Y, Oh J, Huh S, Kawachi I. The effects of employment conditions on smoking status and smoking intensity: the analysis of Korean labor \& income panel 8(th)-10(th) wave. PLoS One. 2013;8(2):e57109. https://doi.org/10.1371/ journal.pone.0057109.

39. Min JY, Park SG, Hwang SH, Min KB. Disparities in precarious workers' health care access in South Korea. Am J Ind Med. 2016;59(12):1136-44. https://doi.org/10.1002/ ajim. 22658 .

40. Steele EJ, Giles LC, Davies MJ, Moore VM. Is precarious employment associated with women remaining childless until age 35 years? Results from an Australian birth cohort study. Hum Reprod. 2014;29(1):155-60. https://doi. org/10.1093/humrep/det407.

41. Ojala S, Pyöriä P. Precarious work and the risk of receiving a disability pension. Scand J Public Health. 2019;47(3):293300. https://doi.org/10.1177/1403494818804106.

42. Benach J, Vives A, Tarafa G, Delclos C, Muntaner C. What should we know about precarious employment and health in 2025 ? Framing the agenda for the next decade of research. Int J Epidemiol. 2016;45(1):232-8. https://doi.org/10.1093/ ije/dyv342.

43. Muntaner C, Solar O, Vanroelen C, Martinez JM, Vergara M, Santana V, et al. Unemployment, informal work, precarious employment, child labor, slavery, and health inequalities: pathways and mechanisms. Int J Health Serv. 2010;40(2):281-95.

44. Wagenaar AF, Kompier MA, Houtman IL, van den Bossche SN, Taris TW. Employment contracts and health selection: unhealthy employees out and healthy employees in? J Occup Environ Med. 2012;54(10):1192-200. https://doi. org/10.1097/JOM.0b013e3182717633.

45. Hunefeld L, Koper B. Fixed-term Employment and Job Insecurity (JI) as Risk factors for Mental Health. A Review of International Study Results. E-J Int Comp Labour. 2016;5:1-22.

46. Benach J, Muntaner C, Benavides FG, Amable M, Jodar P. A new occupational health agenda for a new work environment. Scand J Work Environ Health. 2002;28(3):191-6. https://doi.org/10.5271/sjweh.664.

47. Van Aerden K, Moors G, Levecque K, Vanroelen C. Measuring Employment Arrangements in the European Labour Force: A Typological Approach. Soc Indic Res. 2014;116(3):771-91. https://doi.org/10.1007/s11205-0130312-0.

48. Matilla-Santander N, Lidón-Moyano C, González-Marrón A, Bunch K, Martín-Sánchez JC, Martínez-Sánchez JM. Measuring precarious employment in Europe 8 years into the global crisis J Public Health. 2019;41(2):259-67. https:// doi.org/10.1093/pubmed/fdy114.

49. U.S. Bureau of Labor Statistics. Contingent and Alternative Employment Arrangements Summary. U.S. Department of Labor; 2018 [cited 2019 2/26/2019]; Available from: https:// www.bls.gov/news.release/pdf/conemp.pdf. 
50. Lee SS. High non-standard employment rates in the Republic of Korea and Japan: analyzing policy configurations with fuzzy-set/QCA. Policy Soc. 2013;32(4):333-44. https://doi. org/10.1016/j.polsoc.2013.10.005.

51. Abdul Karim S, Eikemo TA, Bambra C. Welfare state regimes and population health: integrating the East Asian welfare states. Health Policy. 2010;94(1):45-53. https://doi. org/10.1016/j.healthpol.2009.08.003.

52. Clement W, Mathieu S, Prus S, Uckardesler E. Precarious lives in the new economy: Comparative intersectional analysis. Gender and the contours of precarious employment: London, UK: Routledge; 2009. p240-55.

53. Menéndez M, Benach J, Muntaner C, Amable M, O'Campo P. Is precarious employment more damaging to women's health than men's? Soc Sci Med 2007 Feb;64(4):776-81. https://doi.org/10.1016/j.socscimed.2006.10.035.

54. Ansoleaga E, Díaz X, Mauro A. [Psychosocial risks, quality of employment, and workplace stress in Chilean wageearning workers: a gender perspective]. Cad Saude Publica. 2016;32(7).
55. OECD. International Migration Outlook: Annual Report Paris: OECD Publishing; 2007.

56. Forde C, Slater G, Green F. Agency working in Britain: what do we know. Centre for Employment Relations Innovation and Change Policy Report. 2008 (2).

57. McKay S. Trade unions and recent migration: organising challenges in an enlarged EU. WLRI Working Paper, 2008.

58. Waldinger R, Lichter MI. How the other half works: Immigration and the social organization of labor. Berkeley, CA: Univ of California Press; 2003.

59. Castles S, Kosack G. Immigrant workers and class structure in Western Europe. London, UK: Oxford University Press; 1973.

60. Vosko LF. Managing the margins: Gender, citizenship, and the international regulation of precarious employment. London, UK: Oxford University Press; 2010.

61. Olsthoorn M. Measuring Precarious Employment: A Proposal for Two Indicators of Precarious Employment Based on SetTheory and Tested with Dutch Labor Market-Data. Soc Indic Res. 2014;119(1):421-41. https://doi.org/10.1007/s11205013-0480-y.

Received for publication: 28 August 2019 